\title{
Interpretation of pleural biopsy specimens and aspirates with the immunoperoxidase technique
}

\author{
AMANDA HERBERT, PATRICK J GALLAGHER \\ From the Department of Pathology, Southampton General Hospital, Southampton
}

SUMMARY In pleural biopsy specimens and histological sections from the fibrin clots of pleural fluid aspirates it may be difficult to distinguish reactive mesothelial cells from malignant mesothelial cells and metastatic carcinoma. Reactive pleurisy with effusion is usually associated with loss of cohesion and exfoliation of mesothelial cells, which is consistent with the hypothesis that they act as facultative histiocytes. A series of biopsy specimens and sections of clots from benign and malignant pleural effusions have been stained by the immunoperoxidase technique for the histiocytic markers $\alpha_{1}$-antitrypsin, $\alpha_{1}$-antichymotrypsin, and lysozyme (muramidase). Eight cases of mesothelioma were included. Mesothelial cells when seen as a monolayer lining the pleural surface were negative. Reactive mesothelial cells, usually seen as exfoliated cells, were consistently strongly positive for $\alpha_{1}$-antichymotrypsin and more variably for $\alpha_{1}$-antitrypsin and lysozyme. Malignant cells, whether from carcinoma or from mesothelioma, were usually but not always negative. Consequently immunohistochemical staining for $\alpha_{1}$-antichymotrypsin is often helpful in distinguishing reactive mesothelial cells from malignant cells.

In a recent study of the morphological interpretation of pleural biopsy specimens and sections of the fibrin clots from aspirates we observed that reactive pleurisy was usually associated with loss of cohesion and exfoliation of mesothelial cells. ${ }^{1}$ This helped to distinguish reactive from neoplastic mesothelium, which was suggested by cohesive papillary proliferation. Despite this it may be difficult on purely morphological criteria to differentiate reactive from neoplastic mesothelial cells on the one hand and from metastatic carcinoma on the other. The same problem exists in the interpretation of cytological preparations of pleural fluid, where reactive mesothelial cells may be difficult to distinguish from malignant cells, particularly in certain conditions such as pulmonary infarction and hepatic cirrhosis. Furthermore, the cytological diagnosis of mesothelioma tends to be less reliable than that of carcinoma, ${ }^{2-4}$ although cytological examination usually yields more positive diagnoses of malignancy than does closed biopsy. ${ }^{15}$

Two approaches have been made in the histochemical interpretation of pleural fluids. One is to stain positively for the malignant cells. Epithelial

Address for reprint requests: Dr A Herbert, Department of Pathology, Level E, South Pathology and Laboratory Block, Southampton General Hospital, Southampton SO9 4XY. membrane antigen has proved helpful in this respect as it shows a constant though quantitative difference in staining between most malignant cells and reactive mesothelial cells. ${ }^{6}$ The other approach is to stain positively for the reactive cells. Mesothelial cells, like macrophages and histiocytes, have been shown to contain enzymes such as non-specific esterase and naphthol A-SD chloracetate, ${ }^{7}$ but the staining patterns have not been found to be useful for distinguishing benign and malignant cells. ${ }^{8}$ Furthermore, these enzymes cannot be readily demonstrated in formalin-fixed paraffin-embedded tissue.

One constant observation has been that reactive mesothelial cells contain brightly staining periodicacid-Schiff '(PAS)-positive, diastase-resistant granules in their cytoplasm..$^{9-11}$ This renders the PAS technique of little value in the distinction of reactive cells from adenocarcinoma, which often contains intracytoplasmic PAS-positive, diastase-resistant epithelial mucin. Similar granules are also present in histiocytes such as pulmonary macrophages and they correlate with positive staining for the glycoprotein protease inhibitor $\alpha_{1}$-antitrypsin. This is now known to be synthesised by histiocyte ${ }^{12}$ and rat pulmonary macrophages, ${ }^{13}$ although not being entirely specific for this series of cells. Alpha-1-antichymotrypsin has also been shown to be positive in malignant histiocytosis $^{14}$ and malignant fibrous histiocytoma. ${ }^{15}$ 
Alpha-1-antitrypsin as well as $\alpha_{1}$-antichymotrypsin and lysozyme are useful markers for histiocytes, which can be readily identified in formalin-fixed paraffin-embedded histological sections. The object of this study was to examine their range of staining in normal, reactive, and neoplastic mesothelium and in metastatic carcinoma. This technique has advantages for the interpretation of pleural biopsy specimens.

\section{Methods}

\section{PATIENTS STUDIED}

The material was taken from a series of 95 closed biopsies, 23 open biopsies and pleurectomies, and 158 sections of pleural clots, which represented all the surgical specimens of pleura received from the Southampton General and Western Hospitals during one year (1976). Sections from all 22 closed biopsy specimens that included recognisable reactive or neoplastic mesothelium were cut and stained. Specimens from a selection of open biopsies, including cases of mesothelioma, fibrous pleurisy, empyema, and eosinophilic pleuritis associated with pleurectomies for pneumothorax, were also stained, as were eight fibrin clots from cases of proved reactive pleurisy and 16 fibrin clots from cases of proved malignant effusion. In some of the small biopsy specimens there was no mesothelial tissue left in the block when they were recut. Patients' notes had been available for follow-up and confirmation of diagnoses.

\section{IMMUNOPEROXIDASE STAINING}

Sections were stained for $\alpha_{-}$-antitrypsin, $\alpha_{1}$ antichymotrypsin, and lysozyme by the unlabelled antibody peroxidase-antiperoxidase (PAP) technique $^{16}$ with prior trypsinisation, ${ }^{17}$ rabbit antihuman serum obtained from Dako-immunoglobulins being used. For $\alpha$-antitrypsin and lysozyme control sections were blocked with purified antigens, but these were not available for $\alpha_{-}$-antichymotrypsin. As a negative control whole rabbit serum was substituted for the rabbit antihuman primary antiserum in each of the staining procedures.

\section{Results}

NORMAL AND REACTIVE MESOTHELIUM In six cases in which there was a single layer of cuboidal mesothelial cells lining the pleural surface or inflammatory bands and adhesions these cells were found to be negative for $\alpha_{1}$-antitrypsin, $\alpha_{1}$ antichymotrypsin, and lysozyme. Diffuse pale cytoplasmic staining was occasionally noted, but this is regarded as a non-specific finding. Positivity is taken as granular intracytoplasmic staining.
In eight cases clumps of reactive mesothelial cells were included which were either closely applied to the surface of a reactive pleurisy or exfoliated. These cells stained strongly for $\alpha_{1}$-antichymotrypsin and rather more variably for $\alpha_{1}$-antitrypsin and lysozyme.

The same staining pattern was seen in the exfoliated cells in eight fibrin clots from pleural effusions proved to be reactive (fig 1-3). Granulation tissue lining and chronic fibrous pleurisy organising empyema (four cases stained) showed strong staining of tissue histiocytes for $\alpha_{1}$-antitrypsin, $\alpha_{1}$ antichymotrypsin, and lysozyme. Surface mesothelial cells were not seen in these cases.

Giant cell histiocytes, as seen in tuberculous empyema and the pleuritis associated with pneumothorax, showed strong positive staining for lysozyme but were negative for $\alpha_{1}$-antitrypsin and $\alpha_{1}$ antichymotrypsin. These findings are summarised in table 1 .

\section{MESOTHELIOMA}

Sections of the final, definitive thoracotomy or postmortem specimens were stained from eight patients in this series who proved to have malignant mesothelioma. The staining reactions are summarised in table 2 .

All sections were negative for lysozyme. Two out of eight showed focal fine granular staining for $\alpha_{1}$ antitrypsin in epithelial-type cells. Four out of eight showed similar focal staining for $\alpha_{1}$-antichymotrypsin (figs 4 and 5). In one case there was also some focal intracytoplasmic staining in fibroblastic areas. In all these cases the majority of the tumour cells were negative and the positive staining was less intense than seen in reactive exfoliated mesothelial cells.

Sheets of abnormal mesothelial cells and papillary proliferations stained in three small biopsy specimens from patients later shown to have mesothelioma were negative for both protease inhibitors and lysozyme. Exfoliated papillary structures in pleural clots from two patients later shown to have mesothelioma were also negative.

\section{METASTATIC CARCINOMA}

Fourteen sections from fibrin clots of proved carcinomatous malignant effusions and four biopsy specimens in which there was a mixture of malignant cells and reactive mesothelial cells were stained. The staining reactions for $\alpha_{1}$-antichymotrypsin, which was most sensitive for demonstrating reactive mesothelial cells, are summarised in table 3 . There were no instances of $\alpha_{1}$-antitrypsin staining in the absence of $\alpha_{1}$-antichymotrypsin in benign or malignant cells. The background of reactive cells in these biopsy specimens and clots stained strongly for $\alpha_{1-}$ antichymotrypsin, whereas in most cases the 


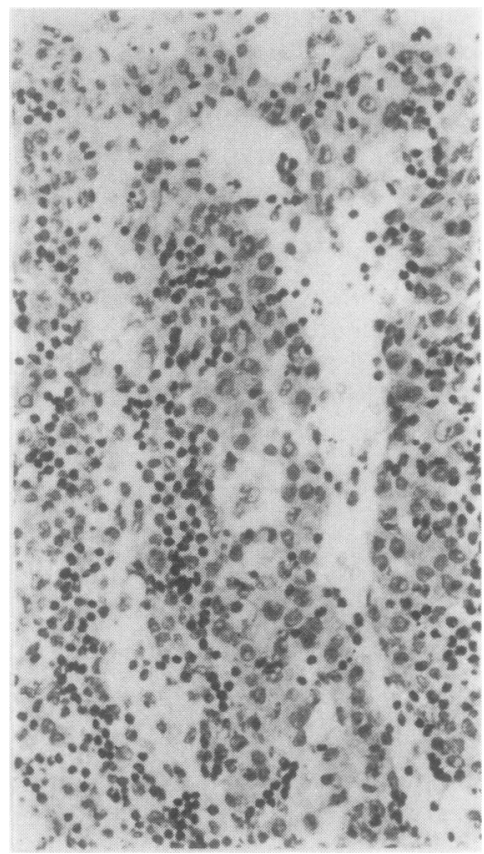

1

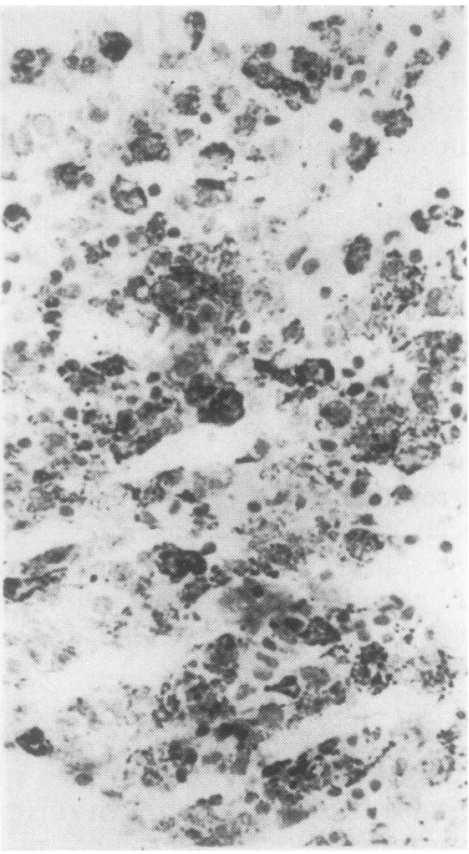

2

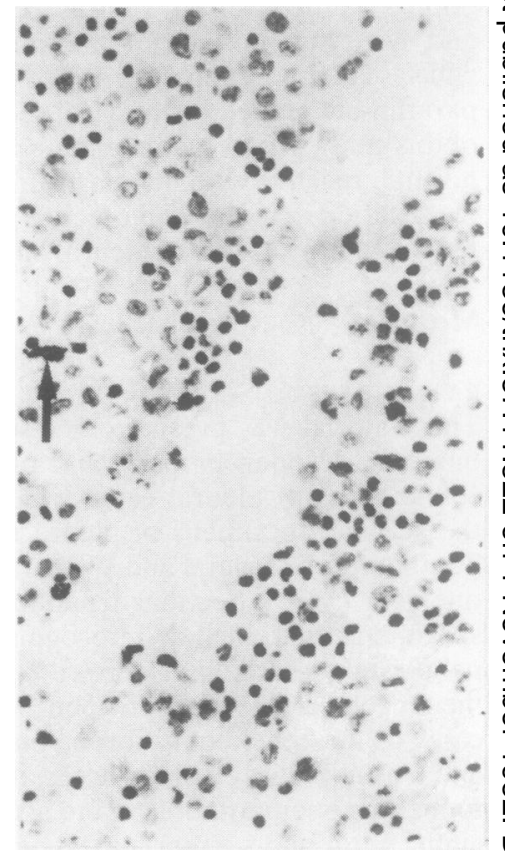

3

Figs 1-3 Pleural fluid clot from a patient with reactive pleurisy. 1 Mixed lymphocytes and reactive mesothelial cells. (Haematoxylin and eosin, $\times 400$.) 2 Reactive cells staining intensively for $\alpha$-antichymotrypsin. (Peroxidaseantiperoxidase, $\times 540$ ). 3 Only occasional cells (arrow) staining for lysozyme. (Peroxidase-antiperoxidase, $\times 400$.)

Table 1 Results of immunoperoxidase staining of reactive mesothelial cells and histiocytes

\begin{tabular}{lllll}
\hline & No of cases & $\alpha_{1}$-Antitrypsin & $\alpha_{1}$-Antichymotrypsin & Lysozyme \\
\hline $\begin{array}{l}\text { Surface lining mesothelial cells } \\
\begin{array}{l}\text { Reactive and exfoliated } \\
\text { mesothelial cells }\end{array}\end{array}$ & 6 & - & - & - \\
$\begin{array}{l}\text { Tissue histiocytes in } \\
\text { pleural granulation tissue }\end{array}$ & 16 & \pm & + & \pm \\
\begin{tabular}{l} 
Giant cells \\
\hline
\end{tabular} & 4 & + & + & + \\
\hline
\end{tabular}

+Strong granular cytoplasmic staining; \pm weak or variable staining; - no staining reaction.

Table 2 Results of immunoperoxidase staining of malignant mesotheliomas

\begin{tabular}{clll}
\hline & $\alpha_{1}$-Antitrypsin & $\alpha_{1}$-Antichymotrypsin & Lysozyme \\
\hline Epithelial & - & - & - \\
Mixed & - & - & - \\
,$"$ & \pm & \pm & - \\
$"$, & \pm & \pm & - \\
$"$, & \pm & \pm & - \\
$"$, & - & - & - \\
,$"$ & - & \pm & - \\
\hline
\end{tabular}

士Focal intracytoplasmic staining; - no staining reaction.
Table 3 Alpha-1-antichymotrypsin staining of malignant cells (background of reactive cells strongly positive in all cases)

\begin{tabular}{|c|c|c|c|}
\hline & Strongly positive & Weakly positive & Negative \\
\hline $\begin{array}{l}\text { Carcinoma } \\
\text { Closed biopsy } \\
\text { specimen } \\
\text { Fibrin clot }\end{array}$ & $\begin{array}{l}1 \\
1\end{array}$ & 1 & $\begin{array}{r}3 \\
12\end{array}$ \\
\hline $\begin{array}{c}\text { Mesothelioma } \\
\text { Closed biopsy } \\
\text { specimen } \\
\text { Fibrin clot }\end{array}$ & & & $\begin{array}{l}2 \\
2\end{array}$ \\
\hline
\end{tabular}



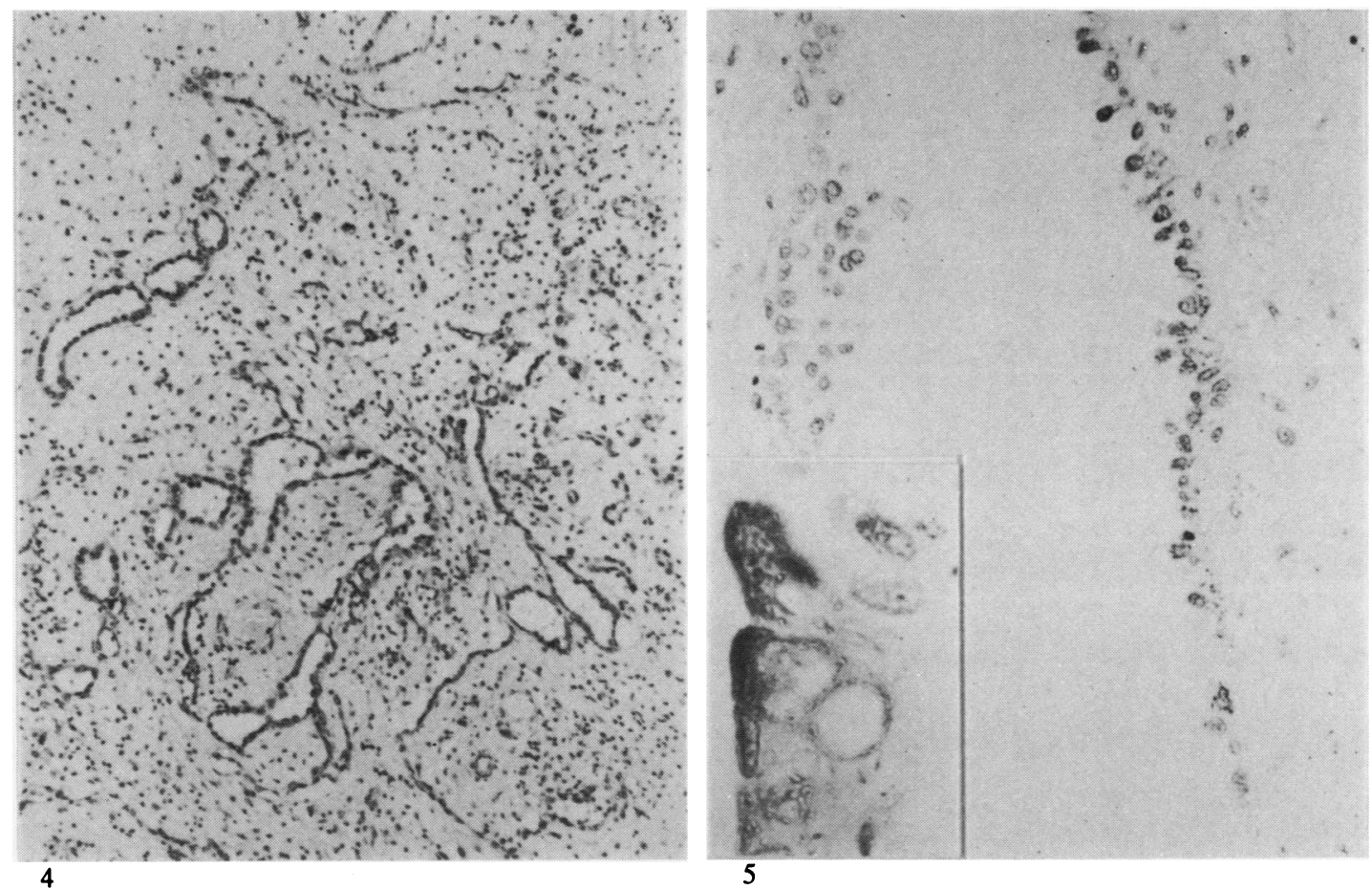

Fig 4 Biphasic malignant mesothelioma with both glandular epithelial and mesenchymal components. (Haematoxylin and eosin, $\times 160$.)

Fig 5 Biphasic malignant mesothelioma (same case as in fig 4): staining for $\alpha_{-}$-antichymotrypsin on right but not on left side. (peroxidase-antiperoxidase, $\times 660)$; detailed view of dark positive cytoplasmic staining in inset $(c \times 2000$.)

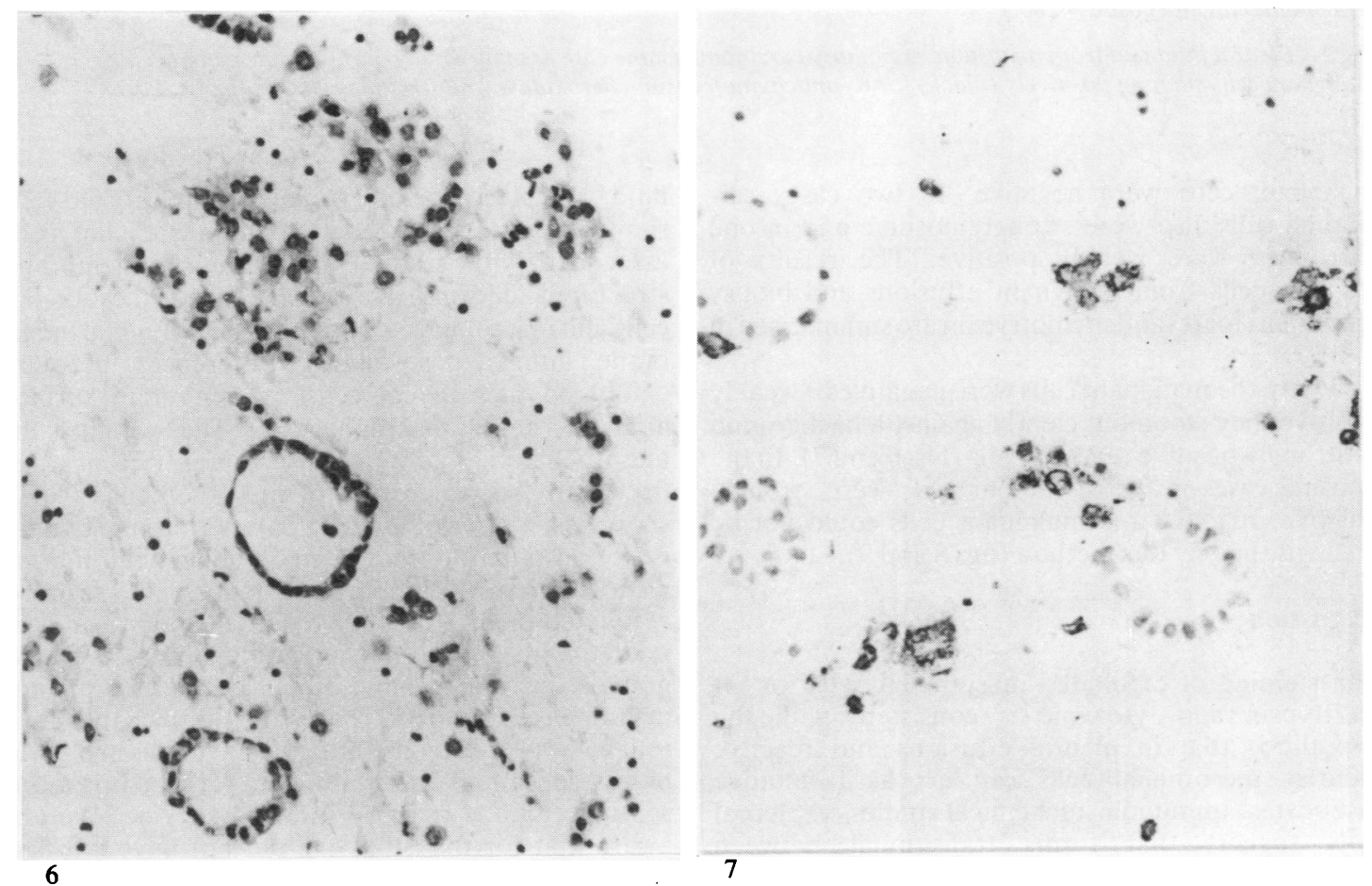

Fig 6 Pleural fluid clot from metastatic mammary carcinoma: two malignant acini stand out against associated reactive mesothelial cells. (Haematoxylin and eosin, $\times 660$.)

Fig 7 Pleural fluid clot from metastatic mammary carcinoma (same case as in fig 6): reactive pleural cells staining positively for $\alpha_{1}$-antichymotrypsin (black) but malignant acini negative. (Peroxidase-antiperoxidase technique, $\times 660$.) 

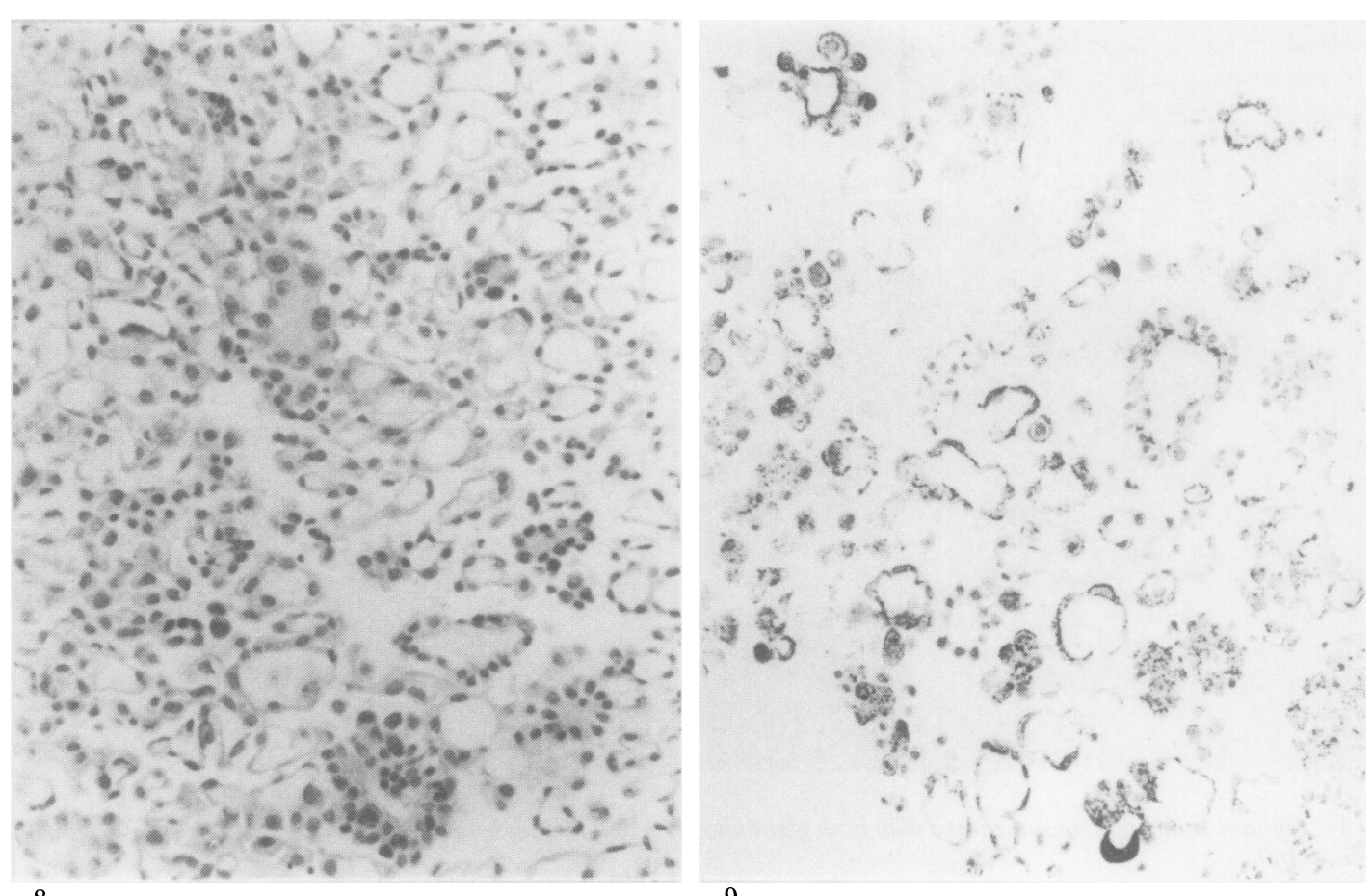

9

Fig 8 Numerous acinar formations in pleural fluid clot from a patient with metastatic mammary carcinoma. (Haematoxylin and eosin, $\times 280$.)

Fig 9 Pleural fluid clot from metastatic mammary carcinoma (same case as in fig 8): in contrast to the general rule malignant cells staining positively (black) for $\alpha_{1}$-antichymotrypsin. (Peroxidase-antiperoxidase technique, $\times 280$.)

malignant cells were negative. In two cases carcinoma cells also were strongly positive and in one case they were weakly positive. The results of staining cells from malignant effusions and biopsy specimens for $\alpha_{1}$-antichymotrypsin are summarised in table 3.

Where the malignant cells were negative or weakly positive they stood out clearly against a background of strongly positive reactive cells (figs 6 and 7). In the unusual cases in which tumour cells were strongly positive, reactive and malignant cells could not be distinguished by this method (figs 8 and 9 ).

\section{Discussion}

The staining of exfoliated mesothelial cells for $\alpha_{1}$ antitrypsin and lysozyme is consistent with the hypothesis that in pleural effusions and reactive pleurisy mesothelial cells can act as facultative histiocytes. Immunohistochemical studies on pleural cells suggest that forms transitional between mesothelial cells and macrophages exist in pleural fluid, ${ }^{9}$ and ultrastructural studies on pleural fluid cells show evidence of exfoliation of mesothelial cells $\underset{x}{\stackrel{0}{x}}$ associated with gradual alterations in membrane $\frac{0}{\sigma}$ structure and forms transitional between mesothelial $\underline{3}$. cells and macrophages. ${ }^{18}$ Staining for epithelial mem- $\delta$ brane antigen also shows differences between exfoliated mesothelial cells, which retain surface 을 antigen, and macrophages. ${ }^{8}$ The ability of $\rightarrow$ mesothelial cells to synthesise $\alpha_{1}$-antitrypsin is reflected in the proportion of mesotheliomas which show focal positive staining. This pattern of staining $\sigma$ is very similar to that seen in malignant fibrous $N$ histiocytomas. ${ }^{15}$ The strong staining of reactive $\underset{\mathrm{N}}{N}$ exfoliated pleural cells for $\alpha_{1}$-antichymotrypsin correlated with previous observations of PAS-positive granules in reactive mesothelial cells and pleural macrophages, and we have found that this is a $\stackrel{?}{?}$ reliable way of demonstrating reactive cells in pleural 0 biopsy specimens and fibrin clots because it is more

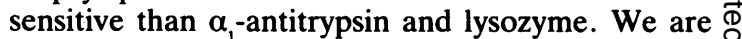
aware that for this study we did not have purified $\mathbb{D}$ blocking antigen for controlling the specificity of the 
$\alpha_{1}$-antichymotrypsin antiserum. In this instance it is to some extent compensated for by the fact that we are emphasising the significance of negative-staining malignant cells with a background of positive-staining reactive cells rather than vice versa.

It must be emphasised that carcinomas of various types can synthesise antiproteases. In this series these enzymes were seen in isolated cases of breast, gastrointestinal, and pulmonary metastases. The practical use of the technique lies in the fact that it helps to identify malignant cells in small biopsy specimens and fibrin clots, which may be difficult to distinguish from reactive mesothelial cells by morphology alone. The fact that neoplastic mesothelial cells are usually negative is sometimes also helpful in assessing small biopsy specimens in the diagnosis of malignant mesothelioma.

We thank the Southampton pathologists and pulmonary physicians for access to their histological material and clinical records, Karen Britten and Mary Judd for the immunohistochemical preparations and illustrations, and Penny Robertson for typing the manuscript.

\section{References}

${ }^{1}$ Herbert A, Gallagher PJ. Pleural biopsy in the diagnosis of malignant mesothelioma. Thorax 1982;37:816-21.

${ }^{2}$ Naylor B. The exfoliative cytology of diffuse malignant mesothelioma J Pathol Bacteriol 1963;86:293-8.

${ }^{3}$ Roberts GH, Campbell GM. Exfoliative cytology of diffuse mesothelioma. J Clin Pathol 1972;25:577-82.

${ }^{4}$ Tao LC. The cytopathology of mesothelioma. Acta Cytol 1979;23:209-13.

${ }^{5}$ Frist B, Kahan AV, Koss LG. Comparison of the diagnostic values of biopsies of the pleura and cytologic evaluations of pleural fluids. Am J Clin Pathol 1979;72:48-51.

${ }^{6}$ To A, Coleman DV, Dearnaley DP, Ormerod MG,
Steele K, Neville AM. Use of antisera to epithelial membrane antigen for the cytodiagnosis of malignancy in serous effusions. J Clin Pathol 1981;34:1326-32.

${ }^{7}$ Efrati P, Nir E. Morphological and cytochemical investigation of human mesothelial cells from pleural and peritoneal effusions. Israel J Med Sci 1976;12:662-73.

${ }^{8}$ Clausen PP, Højgaard K, Thommesen N. The diagnostic value of cytochemical staining for non-specific esterase in the search for cancer cells in effusions. Acta Path Microbiol Scand Sect. A. 1979;87:347-52.

${ }^{9}$ Koss LG. Effusions in the absence of cancer. Diagnostic cytology and its histopathological basis. 3rd ed. Philadelphia: JP Lippincott, 1979:878-910.

${ }^{10}$ Pfitzer P, Huth F. Alcian-PAS positive granules in mesothelioma and mesothelial cells. Acta Cytol 1966;10:205-13.

${ }^{11}$ Foot NC. The identification of mesothelial cells in sediments of pleural effusions. Cancer 1959;12:429-37.

${ }^{12}$ Isaacson P, Jones DB, Millward-Sadler GH, Judd MA, Payne S. Alpha-1-antitrypsin in human macrophages. $J$ Clin Pathol 1981;34:982-90.

${ }^{13}$ White RR, Lee DK, Habicht GS, Janoff A. Secretion of $\alpha$ protease inhibitor by cultured rat alveolar macrophages. Am Rev Respir Dis 1981;123, No 4 part 2 (suppl): 222.

${ }^{14}$ Meister P, Huhn D, Nathrath W. Malignant histiocytosis. Immunohistochemical characterization on paraffin embedded tissue. Virchows Arch A Path Anat Histol 1980;385:233-46.

${ }^{15}$ du Boulay CEH. Demonstration of $\alpha_{1}$ antitrypsin and $\alpha_{1}$ antichymotrypsin in fibrous histiocytomas using the immunoperoxidase technique. Am J Surg Pathol 1982;6:559-64.

${ }^{16}$ Sternberger LA. Immunocytochemistry 2nd ed. New York: John Wiley and Sons, 1979:104-69.

${ }^{17}$ Mepham BL, Frater W, Mitchell BS. The use of proteolytic enzymes to improve immunoglobulin staining by the PAP technique. Histochem J 1979;11:34557.

${ }^{18}$ Domagala W, Koss LG. Configurations of surfaces of cells in effusions by scanning electron microscopy. In: Koss LG, Coleman DV, eds. Advances in clinical cytology. London: Butterworths, 1981:270-313. 